\title{
Comparison of Outcome Between Proximal Femoral Plate and Cephalomedullary Nail for Intertrochanteric Femur Fracture Fixation in Dr. Sardjito General Hospital
}

\author{
Andika Dwicahyo*, Tedjo Rukmoyo, Rahadyan Magetsari and Yudha Mathan Sakti \\ Staff of Orthopaedic and Traumatology department, Gadjah Mada University, Yogyakarta, Indonesia
}

Received: 㱕: December 13, 2018; Published: 制: December 20, 2018

*Corresponding author: Andika Dwicahyo, Staff of Orthopaedic and Traumatology department, Gadjah Mada University, Yogyakarta, Indonesia

\section{Abstract}

Background: Hip fractures had become an increasing health problem throughout the world in parallel with the global aging population. Many treatment methods have been used for the reduction of intertrochanteric fractures, including extramedullary and intramedullary fixation. The aim of this study was to compare the outcomes of intertrochanteric femur fractures treated with proximal femoral plate (PFP) and cephalomedullary nail (PFNA) in Sardjito general hospital.

Materials and Methods: A total of fifty one patients with intertrochanteric femur fractures treated surgically with either PFP or PFNA in our hospital between January 2013 and December 2017 were included into the study. Patients demographics, type of fracture according to Association for Osteosynthesis/Association for the Study of Internal Fixation (AO/ASIF) classification, and the American Society of Anesthesiologists (ASA) classification system scores, type of surgical procedure (PFP or PFNA), operative details, complications and follow-up scores (Harris Hip Score [HHS]) were recorded.

Results: There're 25 patients in PFP group and 26 patients in PFNA groups with the preoperative characteristics of the patients in both groups were similar. PFP group has higher intraoperative blood loss and number of patients transfused postoperatively compared to PFNA group $(249.2 \pm 74.27 \mathrm{ml}$ and $41.18 \%$ vs $163.9 \pm 113.81 \mathrm{ml}$ and $23.53 \%)$ with $\mathrm{p}<0.05$. There were no significant differences in number of complications occurred (3.92\% vs $1.96 \%$ ) and length of hospital stay (12.08 \pm 5.03 days vs $11.58 \pm 4.31$ days) in both PFP and PFNA group with $p>0.05$. At the last follow-up with $42.63 \pm 17.7$ months in PFP group and 25.05 \pm 11.4 months in PFNA group, there were no significant differences in HHS (80.16 \pm 10.13 vs $84.33 \pm 7.09)$ and number of mortality $(7.5 \%$ vs $2.5 \%)$ with $p>0.05$. There is significant correlation between age and HHS score with negative koefisien $(-0,372)$ and $\mathrm{p}<0.05$.

Conclusion: Both PFP and PFNA fixation in intertrochanteric femur fracture patients resulting good functional outcome with HHS more than 80 at more than 6 months follow-up, however PFNA had advantages in lower intraoperative blood loss and the number of patients need to be transfused postoperatively. Also, the age of patients at the time of surgery correlate negatively with the HHS postoperative.

Keywords: Intertrochanteric Femur Fracture; Proximal Femoral Nail Anti Rotation; Proximal Femoral Plate; Functional Outcome; Harris Hip Score; Cephalomedullary Nail

Abbreviations: PFP: Proximal Femoral Plate; AO/ASIF: Association for Osteosynthesis/Association for the Study of Internal Fixation; HHS: Harris Hip Score

\section{Introduction}

Hip fractures are most common medical problems in many west countries like North America, Europe, and Oceania, with estimated will be increasing every year in the world until reach 6,26 million cases in the year of 2050 [1]. Pertrochanter fractures is a fracture occurring in the region beginning from bacillar neck extracapsular proximally until minor trochanter region before developing to

medullary canal. The intertrochanter and peritrochanter are the common terms for pertrochanter fractures [2]. There're still many controversies regarding the best operative treatment for this kind of fractures especially in osteoporotic and unstable pattern type [3]. These operative treatments including using either intramedullary or extramedullary implant, and many studies already describe and compare the outcome of these several type of fixation [4]. 
The recent popular fixation method is using cephalomedullary nail system such as proximal femoral plate anti-rotation (PFNA) with costly titanium material and the need of fluoroscopy in the implantation procedures.

Other method available is using proximal femoral plate (PFP) with additional locking screw mechanism for porotic and more unstable fracture pattern type [5]. This plate available in stainless steel material and implanted in open approach manner without fluoroscopy. Due to limited available studies that compare the outcome between PFNA and PFP, the objective of this study is to compare the functional outcome between cephalomedullary nail fixation with proximal femoral plate fixation at the follow up more than 6 months post operatively and to know the correlation between the perioperative variables such as age, bleeding, duration, classification, ASA score, and length to surgery to the functional outcome.

\section{Methods}

This is a retrospective study with analytical comparative between two groups of subjects that followed up after more than 6 months postoperative. These groups including the Cephalomedullary group and the Proximal femoral plate group. All the subjects are adult traumatic intertrochanter fracture patients that came to emergency unit in Sardjito general hospital Yogyakarta between January 2013 until December 2017 that underwent fixation surgery using either of both implant with exclusion criteria's including multiple trauma patients, pathologic fractures due to tumors, bone metabolism problems, history of hip surgery and any previous limitation of range of movement. All datas obtained from patient's medical records. Functional outcome measured with standardized Harris Hip Score (HHS) questionnaire6, interviewed and examined by author and 2 assistants by telephone conversation and outpatient clinic examination. HHS for all subjects in both groups collected in 1 month period of July 2018. The collected data from medical records, interview, and examination then analyzed statistically using SPSS software.

\section{Results and Discussion}

There're 211 cases of intertrochanter fractures that came to emergency unit Sardjio general hospital between January 2013 until December 2017, with 51 cases that meets inclusion and exclusion criteria's. Divided two groups with 26 cases of PFNA surgery fixation and 25 cases with PFP surgery fixation. The data then categorized to preoperative data (including demographic data's), intraoperative data, postoperative data, and follow up data (conducted after more than 6 months post-surgery). The detailed datas shown in below tables. The Table 1 showed a demographic distribution and the preoperative status between two groups. All datas distributed normally measured using Saphiro Wilk test and analyzed using t-test. The results show a non-significant difference between two groups and indicated that all the samples are homogen and comparable. Surgery duration, intraoperative blood loss, and number of patients that need transfusion are better in the PFNA group, but statistically the significant results only occur for blood loss and number of patient transfused variables with $\mathrm{p}<0.05$ shown in Table 2.

Table 1: Preoperative data comparison distribution.

\begin{tabular}{|c|c|c|c|}
\hline & Grup PFNA & Grup PFP & $\mathbf{p}$ \\
\hline Number of patients & 26 & 25 & \\
\hline Mean age in years (SD) & $66,2(17,7)$ & $58,9(20,8)$ & 0,184 \\
\hline Number of men $(\%)$ & $13(25,49)$ & $15(29,41)$ & 0,473 \\
\hline \multicolumn{3}{|c|}{ ASA Score } & \multirow{3}{*}{0,679} \\
\hline ASA I & $5(9,8)$ & $6(11,76)$ & \\
\hline ASA II & $21(41,18)$ & $19(37,25)$ & \\
\hline Time (days) from injury to surgery (SD) & $8,9(4,14)$ & $8.4(5,04)$ & 0,687 \\
\hline \multicolumn{3}{|c|}{ Fracture classification: } & \multirow{4}{*}{0,181} \\
\hline 3.1.A.1 (\%) & $11(21,57)$ & $6(11,76)$ & \\
\hline 3.1.A.2 (\%) & $11(21,57)$ & $10(19,6)$ & \\
\hline 3.1.A.3 (\%) & $4(7,84)$ & $9(17,65)$ & \\
\hline
\end{tabular}

Table 2: Intraoperative Variables Data.

\begin{tabular}{|c|c|c|c|}
\hline & Grup PFNA & Grup PFP & p \\
\hline Number of patients & 26 & 25 & \\
\hline Mean (min) surgery duration (SD) & $128,1(47,27)$ & $141,2(29,02)$ & 0,240 \\
\hline Intraoperative (ml) blood loss (SD)* & $163,9(113,81)$ & $249,2(74,27)$ & 0,003 \\
\hline Number of patients transfused (\%)* & $12(23,53)$ & $21(41,18)$ & 0,005 \\
\hline
\end{tabular}

Note: *Significant differences statistically $(\mathrm{p}<0,05)$.

Cite this article: Andika D, Tedjo R, Rahadyan M, Yudha Mathan S. Comparison of Outcome Between Proximal Femoral Plate and Cephalomedullary Nail for Intertrochanteric Femur Fracture Fixation in Dr. Sardjito General Hospital. Biomed J Sci \& Tech Res 12(3)-2018. BJSTR. MS.ID.002256. DOI: 10.26717/ BJSTR.2018.12.002256. 
It could be because the approach used in PFNA was closed approach while the PFP mostly by open approach. And the ability of the radiographer in operating the fluoroscope machine also contribute to the longer duration of surgery in PFNA group. Many other studies shows the PFNA have shorter duration of surgery compared to extramedullary implant fixation surgery [7]. Table 3 showed the complication rate and length of hospital stay between two groups are similar results. The follow up data obtained after 6 months postoperative at minimum showed that the HHS (describe the functional outcome status) between both groups have similar good results (more than 80) with no significant difference statistically (Table 4). Other study that compare the functional outcome between PFNA and other fixation implant also showed similar results of the HHS score with no significant different statistically [7]. There's a weak negative correlation between the variable Age with the HHS score with $\mathrm{p}<0.05$ (Table 5).

Table 3: Postoperative Variables Data.

\begin{tabular}{|c|c|c|c|}
\hline & Grup PFNA & Grup PFP & p \\
\hline Number of patients & 26 & 25 & \\
\hline $\begin{array}{c}\text { Number of complications (\%) } \\
\text { (wound infection) }\end{array}$ & $1(1,96)$ & $2(3,92)$ & 0,529 \\
\hline Length of hospital stay (SD) & $11,58(4,31)$ & $12,08(5,03)$ & 0,703 \\
\hline
\end{tabular}

Table 4: Follow up Variables Data.

\begin{tabular}{|c|c|c|c|}
\hline & Grup PFNA & Grup PFP & p \\
\hline Number of patients & 21 & 19 & \\
\hline Length of last follow-up (SD)* & $25,05(11,36)$ & $42,63(17,69)$ & 0,001 \\
\hline Number of mortality (\%) & $1(2,5)$ & $3(7,5)$ & 0,542 \\
\hline Harris Hip Score (SD) & $84,33(7,09)$ & $80,16(10,13)$ & 0,085 \\
\hline
\end{tabular}

Note: *Significant differences statistically $(\mathrm{p}<0,05)$.

Table 5: Perioperatif Variables Data Correlation to HHS (Spearman rho).

\begin{tabular}{|c|c|}
\hline Perioperative Variables & Correlation to HHS \\
\hline Age $^{*}$ & $0,018(-0,372)$ \\
\hline Intraoperatif bleeding & $0,248(-0,187)$ \\
\hline Duration of surgery & $0,754(-0,051)$ \\
\hline AO type classification & $0,142(-0,236)$ \\
\hline ASA physical status & $0,591(-0,088)$ \\
\hline Length of days to surgery & $0,997(-0,001)$ \\
\hline
\end{tabular}

Note: *Significant differences statistically $(p<0,05)$.

ISSN: 2574-1241

DOI: $10.26717 / B J S T R .2018 .12 .002256$

Andika Dwicahyo. Biomed J Sci \& Tech Res

This work is licensed under Creative Commons Attribution 4.0 License

Submission Link: https://biomedres.us/submit-manuscript.php

\section{Conclusion}

Both PFP and PFNA fixation in intertrochanteric femur fracture patients resulting good functional outcome with HHS more than 80 at more than 6 months follow-up, however PFNA had advantages in lower intraoperative blood loss and the number of patients need to be transfused postoperatively. Also, the age of patients at the time of surgery correlate negatively with the HHS postoperative.

\section{References}

1. Cooper C, Campion G, Melton LJ (1992) Hip fractures in the elderly: a world-wide projection. Osteoporos Int 2(6): 285-289.

2. Russel TA (2009) Intertrochanteric fractures. In: Bucholz RW, Heckman JD, Court-Brown CM, Tornetta P (Eds.), Rockwood and Green's fractures in adults. ( $7^{\text {th }}$ edn.) pp. 1597-1640.

3. Xu YZ, Gen DC, Wang XB (2011) A comparative study on proximal femoral nail anti-rotation and third generation of Gamma nail treating femoral intertrochanteric fracture in the elderly. Chin J Traumatol 27: 33-37.

4. Simmermacher RKJ, Ljungqvist J, Bail H, Hockertz T, Vochteloo AJ, et al. (2008) The new proximal femoral nail antirotation (PFNA) in daily practice: results of a multicentre clinical study. Injury 39(8): 932-939.

5. Simmermacher RKJ, Bosch AM, Van Der Werken C (1999) The AO/ASIF proximal femoral nail (PFN): a new device for the treatment of unstable proximal femoral fractures. Injury 30(5): 327-332.

6. Harris WH (1969) Traumatic arthritis of the hip after dislocation and acetabular fractures: treatment by mold arthroplasty. An end-result study using a new method of result evaluation. J Bone Joint Surg Am 51(4): 737-755.

7. Gormeli Gokay, Korkmaz MF, Gormeli CA, Adanas Cihan, Karatas Turgay (2015) Comparison of femur intertrochanteric fracture fixation with hemiarthroplasty and proximal femoral nail systems. Ulus Travma Acil Cerrahi Derg 21(6): 503-508.

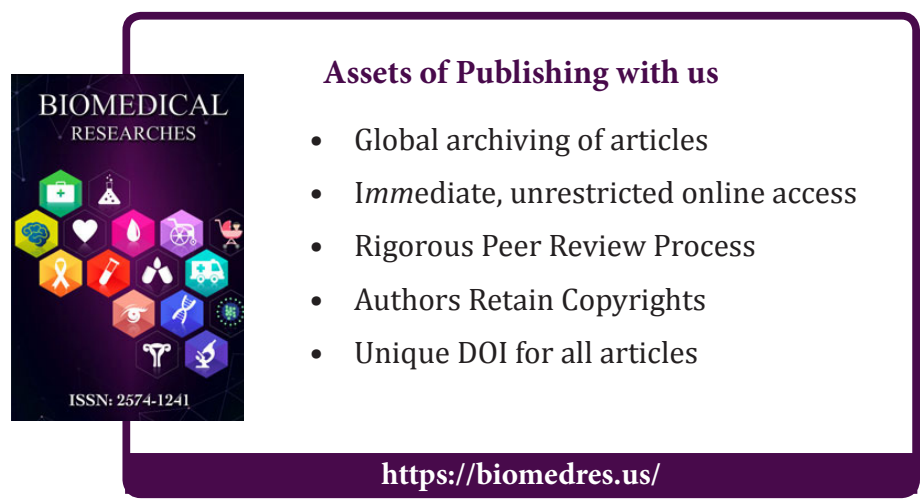

Cite this article: Andika D, Tedjo R, Rahadyan M, Yudha Mathan S. Comparison of Outcome Between Proximal Femoral Plate and Cephalomedullary Nail for Intertrochanteric Femur Fracture Fixation in Dr. Sardjito General Hospital. Biomed J Sci \& Tech Res 12(3)-2018. BJSTR. MS.ID.002256. DOI: 10.26717/ BJSTR.2018.12.002256. 